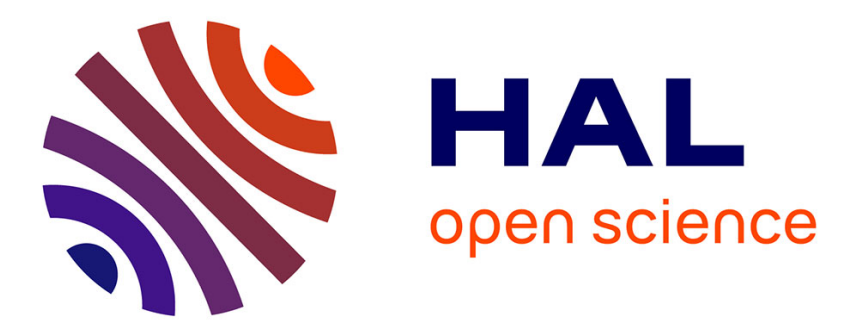

\title{
Wear behavior of PAEK, poly(aryl-ether-ketone), under physiological conditions, outlooks for performing these materials in the field of hip prosthesis
} Jean Geringer, Witold Tatkiewicz, Gilles Rouchouse

\section{- To cite this version:}

Jean Geringer, Witold Tatkiewicz, Gilles Rouchouse. Wear behavior of PAEK, poly(aryl-etherketone), under physiological conditions, outlooks for performing these materials in the field of hip prosthesis. Wear, 2011, 271 (11-12), pp.2793-2803. 10.1016/j.wear.2011.05.034 . hal-00620860

\section{HAL Id: hal-00620860 https://hal.science/hal-00620860}

Submitted on 9 Sep 2011

HAL is a multi-disciplinary open access archive for the deposit and dissemination of scientific research documents, whether they are published or not. The documents may come from teaching and research institutions in France or abroad, or from public or private research centers.
L'archive ouverte pluridisciplinaire HAL, est destinée au dépôt et à la diffusion de documents scientifiques de niveau recherche, publiés ou non, émanant des établissements d'enseignement et de recherche français ou étrangers, des laboratoires publics ou privés. 


\title{
DRAFT \\ WEAR BEHAVIOR OF PAEK, POLY(ARYL-ETHER-KETONE), UNDER PHYSIOLOGICAL CONDITIONS, OUTLOOKS FOR PERFORMING THESE MATERIALS IN THE FIELD OF HIP PROSTHESIS
}

2

3

4

5

6

7

\author{
* : corresponding author \\ Jean Geringer ${ }^{\mathrm{a},{ }^{*}}$, Witold Tatkiewicz $^{\mathrm{a}}$, G. Rouchouse ${ }^{\mathrm{b}}$ \\ ${ }^{a)}$ Ecole Nationale Supérieure des Mines de Saint-Etienne, Center for Health Engineering, \\ Biomechanics and Biomaterials Dpt, Bio-tribocorrosion lab, UMR CNRS 5146, IFR 143, \\ 158 cours Fauriel, 42023 Saint-Etienne Cedex 02, France \\ Tel: +33 477426 688; Fax: +33 477420 157; geringer@emse.fr \\ b CETIM, 7 rue de la presse 42000 Saint-Etienne, France \\ Tel: +33477 794008 ; gilles.rouchouse@cetim.fr
}


1 Abstract

2

This study is focused on performing tribological tests on new materials for orthopaedic

4 implants applications, PAEK (Poly Aryl Ether Ketone) polymer group. The experiments were

5 performed in physiological liquid, at $37^{\circ} \mathrm{C}$, for simulating the human body fluid. PAEK's

6 tribological properties that are wear rate of polymers and wear mechanisms on common

7 metallic alloys used as orthopaedic implants: Co-Cr, 316L SS and Ti-6Al-4V are compared to

8 the gold standard used for hip joint prosthesis, the UHMWPE (Ultra High Molecular Weight

9 PolyEthylene) on the same metal alloys. PEEK (Poly Ether Ether Ketone) and PEKK (Poly

10 Ether Ketone Ketone)/CF (Carbon Fibers) show the lowest wear rate on every counter

11 metallic material; the system UHMWPE on any metal alloys exhibit the highest wear rate

12 although having the lowest friction coefficient. From microscopic images and the evolution of

13 the friction coefficient, a wear mechanism was suggested for each polymeric material.

14

Keywords: PAEK, UHMWPE, metallic alloys, wear rate, hip implants, 


\section{Introduction}

About 800,000 hip prostheses are implanted in Europe, each year. With ageing of population, the implants durability is becoming a health problem and it will be a key point of health issues in the next 10 years. Nowadays the lifetime of hip implants is approximately 15 years. The challenge is to increase their lifetime to avoid an additional surgical operation, involving risks for patients and costs for health organism.

Different materials systems are investigated for the artificial hip joint: hard-hard assembly for head-cup joint, metal-metal or ceramic-ceramic; hard-soft assembly, metalpolymer or ceramic-polymer. This study will focus on the hard-soft artificial joint. Usually, for the acetabular cup, the polymer used is UHMWPE (Ultra High Molecular Weight PolyEthylene) since it gives satisfactory lifetime. However, taking into account the debris generation, the main reason for the failure of implants is the aseptic loosening [1].

Nowadays, so as to replace UHMWPE as a bearing surface, other polymers such as PAEK and their carbon fibers composites are investigated.. These materials are promising in the biomedical field in terms of biocompatibility, low wear rate in comparison with UHWMPE, and machining for artificial cup, hip joint prosthesis [2-4]. For instance, PEKK and its composites are manufactured for spinal implants. In this paper, the tribological behavior of these PAEK polymers will be evaluated for orthopedic implants.

In this work, it is proposed to investigate the tribology of four polymers: UHMWPE, PEEK, PEKK and PEKK CF $30 \%$ against the most usual biocompatible metallic alloys implanted in human body: AISI 316L stainless steel, Ti-6Al-4V alloy and Co-Cr alloy, i.e. twelve materials systems. The tribological tests will be carried out with respect to a sphere (metals)/plane contact (polymers) in bovine serum which is the closest liquid medium to the human physiological liquid,. The results will be compared to the results of Harsha and Tawari [5]. A tribometer was specifically equipped to perform pin (metallic alloys)-on-disc 
1 (polymers) tests in bovine serum at $37{ }^{\circ} \mathrm{C}$. During tests, the friction coefficient gives

2 information about the wear mechanisms taking place between the materials in contact. The

3 post mortem investigations, i.e. wear volumes and wear zones images, allow classifying the

4 different friction couples. Ultimately, from experimental data and microscopic analyses

5 (optical and SEM images), a wear scenario, for UHMWPE and three different polymeric

6 materials from the PAEK group, will be investigated.

\section{Experimental}

\subsection{Materials}

Tables 1-3 describe the chemical composition of 316L stainless steel, Ti-6Al-4V (or TA6V) alloy and the Co-Cr alloy respectively; these metal alloys will be considered as the "pins" for the tribological investigations. The chemical compositions were obtained by spark optical emission spectrometry.

14

\begin{tabular}{cccccccccccc} 
Elements & $\mathbf{C r}$ & $\mathbf{N i}$ & $\mathbf{M o}$ & $\mathbf{M n}$ & $\mathbf{S i}$ & $\mathbf{C u}$ & $\mathbf{C}$ & $\mathbf{P}$ & $\mathbf{S}$ & $\mathbf{F e}$ \\
\hline Composition $(\% \mathrm{w} / \mathrm{w})$ & 17.05 & 14.55 & 2.80 & 1.73 & 0.40 & 0.10 & 0.02 & 0.02 & $<0.01$ & Bal.
\end{tabular}

Table 1: chemical composition of $316 \mathrm{~L}$ stainless steel

17

\begin{tabular}{ccccccccccc} 
Elements & $\mathbf{A l}$ & $\mathbf{V}$ & $\mathbf{F e}$ & $\mathbf{O}$ & $\mathbf{C r}$ & $\mathbf{N i}$ & $\mathbf{C}$ & $\mathbf{N}$ & $\mathbf{T i}$ \\
\hline Composition $(\% \mathrm{w} / \mathrm{w}$ or $\mathrm{ppm})$ & $5.91 \%$ & $3.87 \%$ & $1096 \mathrm{ppm}$ & $1038 \mathrm{ppm}$ & $137 \mathrm{ppm}$ & $125 \mathrm{ppm}$ & $124 \mathrm{ppm}$ & $53 \mathrm{ppm}$ & $\mathrm{Bal}$ &
\end{tabular}

19

\begin{tabular}{ccccccccc} 
Elements & $\mathbf{C r}$ & $\mathbf{M o}$ & $\mathbf{M n}$ & $\mathbf{S i}$ & $\mathbf{N i}$ & $\mathbf{C}$ & $\mathbf{A l}$ & $\mathbf{C o} \mathbf{C}$ \\
\hline Composition $(\% \mathrm{w} / \mathrm{w})$ & $28.50 \%$ & $5.87 \%$ & 0.78 & 0.46 & 0.25 & 0.037 & 0.02 & $\mathrm{BaT}^{-}$
\end{tabular}

21 Table 3: chemical composition of Co-Cr alloy 
1 Arkema $^{\circledR}$ group) UHMWPE (ISO 5834-2) was obtained from Orthoplastics ${ }^{\circledR}$. Figure 1

2 presents the monomers formula of PEEK and PEKK.

3

4

5

6

7

8

9

10

11

12

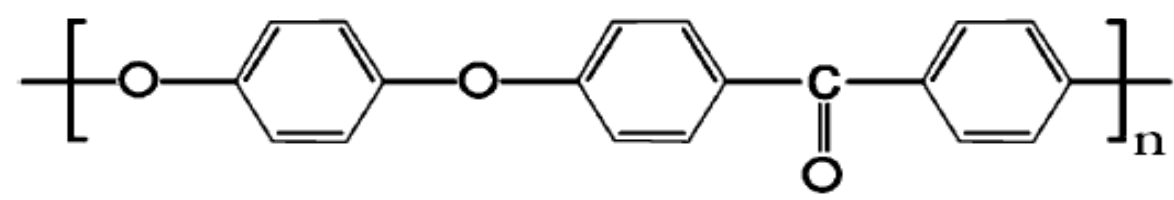

PEEK

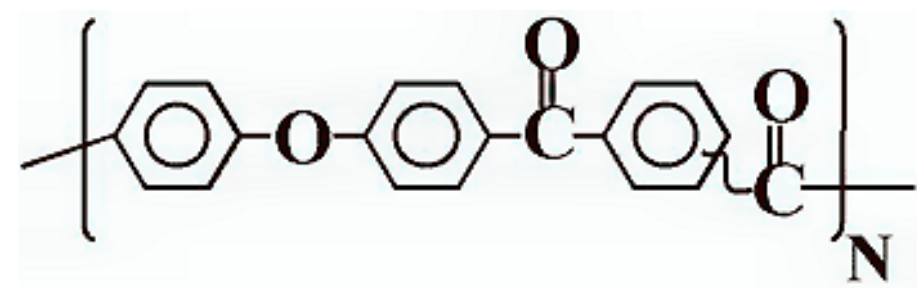

PEKK

Figure 1: PEEK and PEKK monomers formula

The monomer formula of UHMWPE is the following: - $\left(\mathrm{CH}_{2}-\mathrm{CH}_{2}\right)_{\mathrm{n}}$ -

The mechanical properties of all the materials used in the study are presented in Table

4.

\begin{tabular}{|l|c|c|c|c|}
\hline & E / GPa & Poisson's ratio v & Density / $\mathbf{g . c m}$ & UltimateTensile strength / MPa \\
\hline PEKK+CF 30\% & 28.0 & 0.30 & 1.36 & $248 \pm 20$ \\
\hline PEKK & $3.8 \pm 0.4$ & 0.35 & 1.31 & $110 \pm 10$ \\
\hline PEEK & 3.5 & 0.40 & 1.30 & $105 \pm 10$ \\
\hline UHMWPE & $0.7 \pm 0.2$ & 0.46 & 0.94 & $40 \pm 10$ \\
\hline Co-Cr & $200 \pm 10$ & 0.30 & 8.30 & $2000 \pm 200$ \\
\hline 316L SS & $200 \pm 10$ & 0.30 & 7.96 & $630 \pm 50$ \\
\hline Ti-6Al-4V * & $110 \pm 4$ & 0.31 & 4.42 & $1300 \pm 300$ \\
\hline
\end{tabular}

Table 4: mechanical properties of the investigated materials; *data from the manufacturers datasheet and from internal characterizations. 
The polymer materials were supplied either with a disc shape or a rod shape and were

2 machined to the right dimensions, then polished on an automatic machine following the

3 conditions presented in Table 5. As far as the metallic cylinders are concerned, they were

4 machined and polished on a lathe. The cylinder was fixed to a spindle and polishing papers

5 then discs were manually maintained in contact with the sphere rims: the pin.

6

\begin{tabular}{|l|l|l|l|l|}
\hline & Abrasive factor & Time / min & Force / daN & Velocity / RPM \\
\hline PAEKs & Abrasive paper 600 & $5 \mathrm{~min}$ & 11 & 150 \\
\cline { 2 - 5 } & Abrasive paper 1200 & $5 \mathrm{~min}$ & 11 & 150 \\
\cline { 2 - 5 } & Abrasive paper 4000 & $5 \mathrm{~min}$ & 11 & 150 \\
\cline { 2 - 5 } & $3 \mu \mathrm{m}$ diamond paste & $5 \mathrm{~min}$ & 5.5 & 300 \\
\cline { 2 - 5 } & Colloidal silica & $5 \mathrm{~min}$ & 5.5 & 200 \\
\hline UHMWPE & Abrasive paper 80 & $1 \mathrm{~min}$ & 5.5 & 200 \\
\cline { 2 - 5 } & Abrasive paper 120 & $1 \mathrm{~min}$ & 5.5 & 200 \\
\cline { 2 - 5 } & Abrasive paper 600 & $1 \mathrm{~min}$ & 5.5 & 200 \\
\cline { 2 - 5 } & Abrasive paper 1200 & $2 \mathrm{~min}$ & 5.5 & 200 \\
\cline { 2 - 5 } & Abrasive paper 4000 & $3 \mathrm{~min}$ & 5.5 & 200 \\
\cline { 2 - 5 } & Colloidal alumina & $5 \mathrm{~min}$ & 5.5 & 200 \\
\hline Cylinders & Abrasive paper 4000 & $5.5 \mathrm{~min}$ & MANUAL & \\
\cline { 2 - 5 } & $6 \mu \mathrm{m}$ diamond paste & $5.5 \mathrm{~min}$ & MANUAL & \\
\cline { 2 - 5 } & $3 \mu \mathrm{m}$ diamond paste & $5.5 \mathrm{~min}$ & MANUAL & \\
\cline { 2 - 5 } diamond paste & $5.5 \mathrm{~min}$ & MANUAL & \\
\hline
\end{tabular}

7

8

9

10

11

12

13

14

15

16

17

1

Table 5: Polishing protocols for PAEKs (PEEK, PEKK, PEKK+CF), UHMWPE and cylinders made out metallic alloys.

Examples of polished surfaces so-obtained are presented in Figure 2. The top of the cylinders' hemisphere was homogenously smooth over area that exceeded the approximated diameter of contact. Scratches of machining were no longer visible. Analyzes, especially EDX analysis, were carried out to be confirm that, with the polishing protocol, no colloidal silica particles were incrusted in the polymer material. 

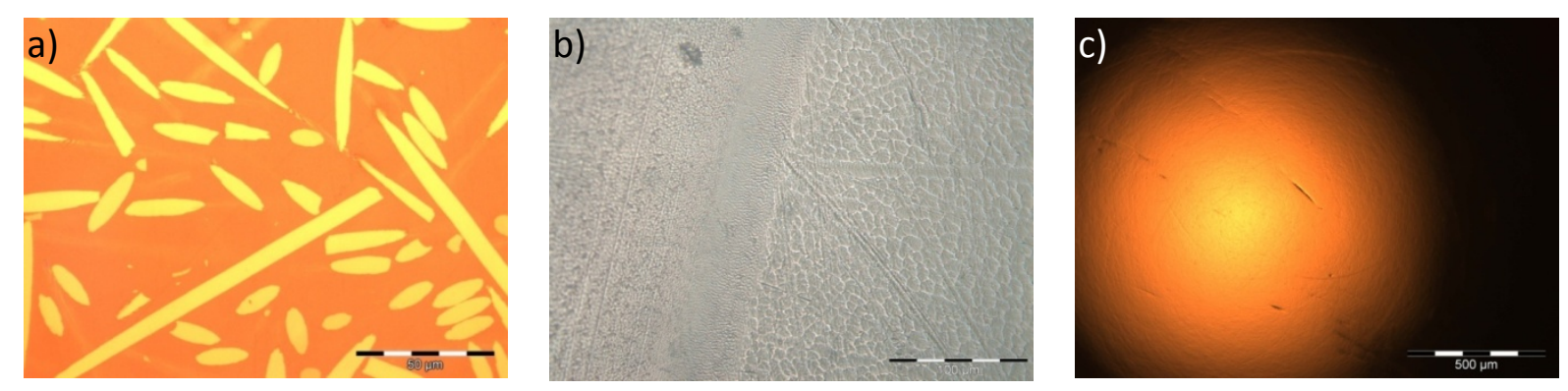

2 Figure 2: Surfaces after polishing: a) PEKK + CF 30\%, b) UHMWPE (right side of picture), c) 3 Co-Cr cylinder

\subsection{SEM and 3D profilometry}

The polymer and metallic samples were observed with a Scanning Electron

7 Microscope (SEM) JEOL 6400 coupled with an EDS probe. A particular attention was paid 8 on insulating polymer, especially PAEK, for performing the SEM images. It is the reason why 9 , after friction tests, a gold sputtered layer covers the worn surfaces in order to highlight transferred particles between two materials in contact and to understand the wear behavior for

11 all friction couples. The $3 \mathrm{D}$ profilometry was investigated thanks to a SOMICRONIC ${ }^{\circledR}$ 12 profilometer. Data were treated by the Surfascan ${ }^{\circledR} 3 \mathrm{D}$ software. Table 6 gives the surface 13 quality features reached for each polymeric material.

15

16 17

18 It is worth noting that the minimum Ra value corresponds to PEEK. It is the easiest material

Table 6: 2D Ra parameter for discs; measure length of $0.5 \mathrm{~mm}$. for the polishing step. On the contrary, the UHMWPE material was not easily polished. The Ra value can be compared to a machined surface.

\begin{tabular}{|l|c|}
\hline \multicolumn{1}{|c|}{ Polymer } & \multicolumn{1}{c|}{$\mathrm{Ra} / \mu \mathrm{m}$} \\
\hline PEKK CF & $0.155 \pm 0.05$ \\
\hline PEKK & $0.126 \pm 0.05$ \\
\hline PEEK & $0.068 \pm 0.05$ \\
\hline UHMWPE & $1.690 \pm 0.1$ \\
\hline
\end{tabular}




\subsection{Tribocorrosion device}

3

Figure 3 presents the friction device (tribometer) in which was described in details in a

4 previous work [6]. The Normal load was equal to $30.4 \mathrm{~N}$ and was applied by a calibrated rod

5 fixed on the pin support. The alignment and parallelism of the pin support was carefuly

6 verified before each test. The pin, made out of metallic alloy (Co-Cr, 316L SS or Ti-6Al-4V),

7 was firmly pushed in the pin support. The spherical pin allows a perfect sphere/plan contact,

8 i.e. a disk, contact area, according to the contact configuration. The actual tangential load, and

9 so the friction coefficient, were continuously monitored. The tribological conditions are summarized in Table 7. The test last for 8 hours to pass the running-in period.

a)

Load Transducer

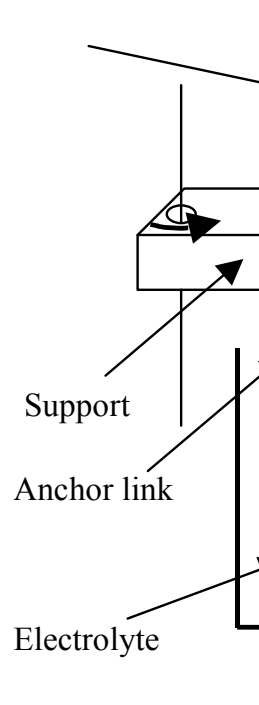

11

12

13 Figure 3: Pin on disc tribometer; a) scheme of pin-disk assembly; b) device image. b)

$\mathrm{F}_{\mathrm{n}}$

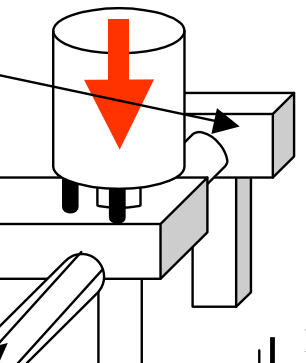

Pin, metallic alloy Bovine serum

Disk, polymer double wall envelop
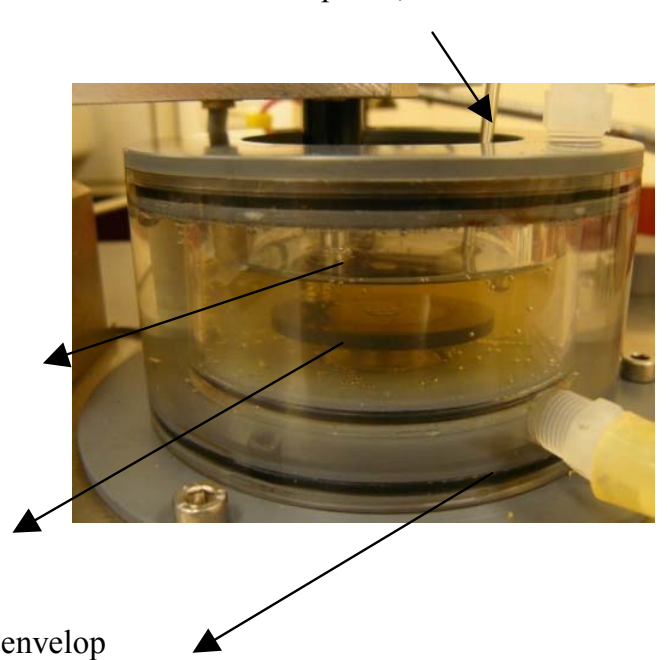


\begin{tabular}{|l|c|c|}
\hline \multicolumn{1}{|c|}{ Parameter } & Unit & Value \\
\hline Rotation radius & $\mathrm{mm}$ & 10.0 \\
\hline Frequency & $\mathrm{Hz}$ & 1.0 \\
\hline Speed & $\mathrm{mm} . \mathrm{sec}^{-1}$ & 62.8 \\
\hline Time of experiment & $\mathrm{h}$ & 8.0 \\
\hline Total distance & $\mathrm{m}$ & 1809.6 \\
\hline Load & $\mathrm{N}$ & 30.4 \\
\hline
\end{tabular}

3 Table 7: Tribological conditions: displacement and charge specifications.

The samples were immersed into the same solution used for the wear tests, that is the

6 bovine serum (PAA Laboratories $\mathrm{GmbH}$, Austria) diluted in proportion 1:4 with distilled

7 water. One part of sodium azide (ultra pure: $>99.5 \%$; Fluka Analytical) per 100 parts of 8 resulting solution was added, according to the ISO 14242-1. Sodium azide is used as an anti9 oxidant to avoid proteins alteration. The electrochemical behavior, and consequently the wear 10 behavior, of metal alloys depend on anti-oxidant content in a proteins solution [7]. experiments that were performed: 3 for each contact type so 36 experiments in total.

\begin{tabular}{|c|c|c|c|}
\hline & $\mathrm{CoCr}$ & $316 \mathrm{~L}$ & TA6V \\
\hline PEKK CF & $X X X$ & $X X X$ & $X X X$ \\
\hline PEKK & $X X X$ & $X X X$ & $X X X$ \\
\hline PEEK & $X X X$ & $X X X$ & $X X X$ \\
\hline UHMWPE & $X X X$ & $X X X$ & $X X X$ \\
\hline
\end{tabular}

14 Table 8: Summarizing of the tests number.

Finally, so as to make sure of the repeatability of the tests, samples were dried and

16 conditioned in bovine serum before pin-on-disc tests. This step was added to the protocol in

17 order to take into consideration the absorption of liquids into polymers. 


\subsection{Contact mechanics about the selected couples}

3

Actual pressures and geometry of contact sphere-plan were calculated using Hertz's

4 theory of contact [8-10]:

$$
\begin{array}{ll}
5 & r=\sqrt[3]{\frac{3 \cdot F \cdot R}{E^{*}}} \\
6 & \bar{P}=\frac{F}{\pi \cdot r^{2}}
\end{array}
$$

7 Where:

8 r: contact radius

$9 \quad \bar{P}$ : average pressure,

10 F: normal force to the surface,

11 E*: effective Young's modulus: $\frac{1}{E^{*}}=\frac{\left(1-v_{1}^{2}\right)}{E_{1}}+\frac{\left(1-v_{1}^{2}\right)}{E_{2}}$

12 R: effective radius: $\frac{1}{R}=\frac{1}{R_{1}}+\frac{1}{R_{2}}$

13 In these experiments, $\mathrm{R}_{1}$ is $3 \mathrm{~mm}$ and $\mathrm{R}_{2}$ is infinite (plane sample).

$14 \mathrm{E}_{\mathrm{i}}, v_{\mathrm{i}}, \mathrm{R}_{\mathrm{i}}$ are as follows: Young's modulii, Poisson's ratios and radii of samples respectively.

15 Indexes 1 and 2 refer to metallic samples and polymer sample respectively.

16 The calculated contact radii and average contact pressures are presented in Table 9 and Table $17 \quad 10$.

18

19

\begin{tabular}{|l|c|c|c|}
\hline \multirow{2}{*}{ Contact radii / $\boldsymbol{\mu m}$} & \multicolumn{3}{|c|}{ Metallic material / sphere } \\
\cline { 2 - 4 } Polymer material / disC & Co-Cr & $\mathbf{3 1 6 L}$ & Ti-6Al-4V \\
\hline PEKK CF 30 \% & 136 & & \\
\hline PEKK & 254 & 253 & 141 \\
\hline PEEK & 261 & 260 & 255 \\
\hline UHMWPE & 380 & 380 & 381 \\
\hline
\end{tabular}

Table 9: Contact radii, before friction test, in $\mu \mathrm{m}$, for all investigated contacts 


\begin{tabular}{|l|c|c|c|}
\hline \multicolumn{1}{|c|}{$\begin{array}{c}\text { Average contact } \\
\text { pressure MPa }\end{array}$} & \multicolumn{3}{|c|}{ Metallic materials / sphere } \\
\cline { 2 - 4 } & Co-Cr & 316L & Ti-6Al-4V \\
\hline Polymer material / disC & & & \\
\hline PEKK CF & 529 & 523 & 490 \\
\hline PEKK & 153 & 152 & 151 \\
\hline PEEK & 145 & 144 & 143 \\
\hline UHMWPE & 68 & 68 & 68 \\
\hline
\end{tabular}

3 Table 10: Average contact pressure in MPa for all investigated contacts; values were 4 calculated from the average values of tensile strength

It is worth noting that in the experimental conditions of the tests, a high average

7 contact pressure was involved. To correlate the wear behavior to the mechanical parameters,

8 the ratios of the average contact pressure on tensile strength of each polymer material (PEKK

9 CF $30 \%$, PEKK, PEEK, UHMWPE) were calculated. The ratios are presented in Table 11.

As the polymer materials are brittle, according to the calculated pressures, the debris

11 generation should be promoted in these experimental conditions as confirmed by typical ratios higher than 1. Moreover the higher the ratio is, the higher the wear rate should be. This assumption will be discussed later in details thanks to post mortem analyses.

\begin{tabular}{|l|c|c|c|c|}
\multirow{2}{*}{ Relative pressures } & \multicolumn{4}{|c|}{ Polymer material / disc } \\
\cline { 3 - 5 } Typical ratio & PEKK CF & PEEK & PEKK & UHMWPE \\
\hline Average pressure/Tensile strength & & & & \\
\hline
\end{tabular}

Table 11: Relative pressures, ratio of average contact pressure to tensile strength in contact zone for 4 polymer materials.

\section{Results and discussion}

In this part, a specific attention will be paid to the friction coefficient evolution

21 according to the time, to the wear rate and to the microscopic analyses of the wear track area

22 in order to understand the wear behavior of the tribological systems. 


\section{2}

4 time of 316L SS vs. UHMWPE, PEEK, PEKK and PEKK + CF $30 \%$. After a running-in

5 period, the values of friction coefficient for pure polymers against metallic alloy constantly

6 decreased until they reached a plateau below the initial value. The same trend is observed for

7 each pure polymer/metal couple although the friction behavior depends specifically on the

8 polymer. On the other hand, the behavior of the PEKK composite is different: after 3-5

9 minutes of test, the tangential force was drastically increased. After 100 min following this

10 trend, values start to stabilize but still slightly rising. The most unstable values of the friction

11 coefficient are for the contact 316L/PEKK. This particular evolution might be due to debris

12 generation during the tribology test. Such production of a "third body" allows reaching a very

13 low friction coefficient, comparable to that of UHMWPE material. The question raised then

14 is: is the corresponding wear rate high or low? This question will be discussed further in the paper. 
a)

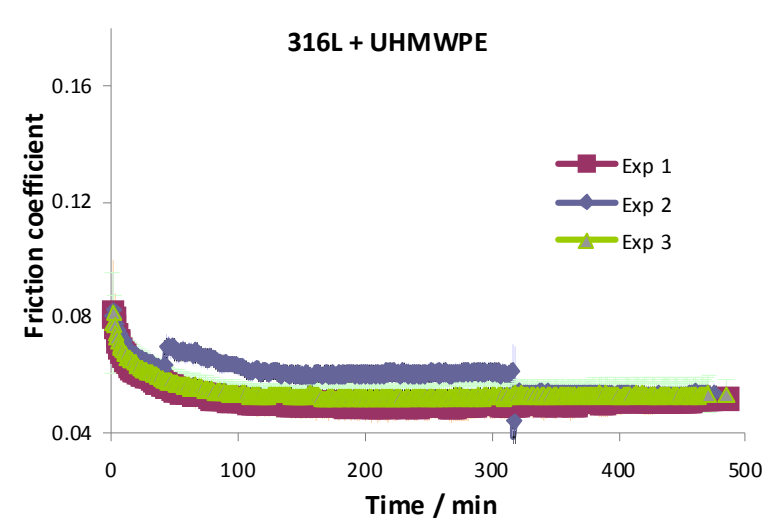

2

3 c)

4

5

6

7

8

9

10

11

12

13 friction coefficient increases with time. .

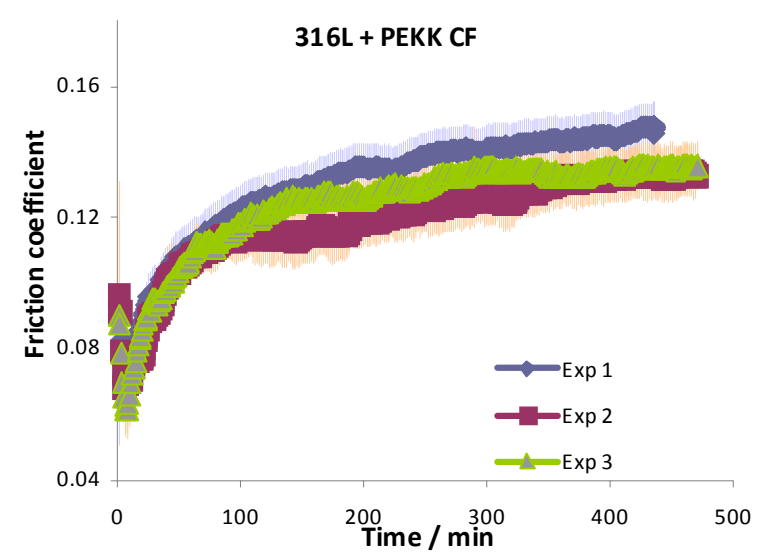
b) PEEK; c) PEKK; d) PEKK CF $30 \%$. b)

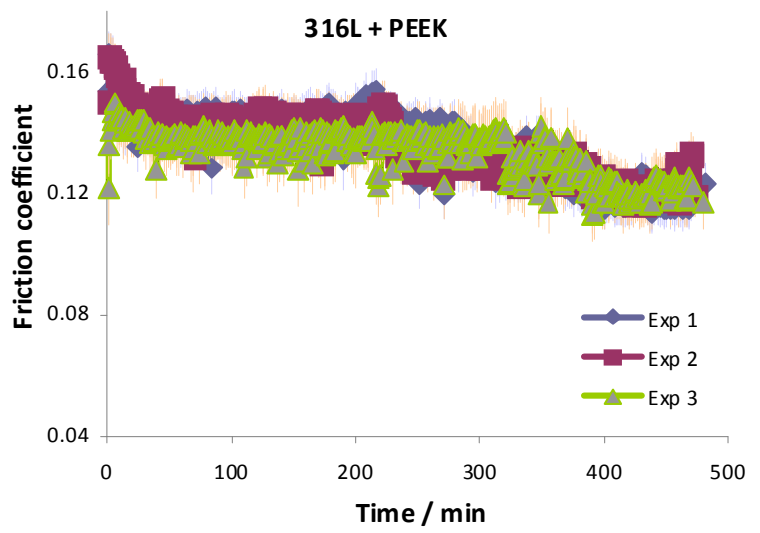

d)

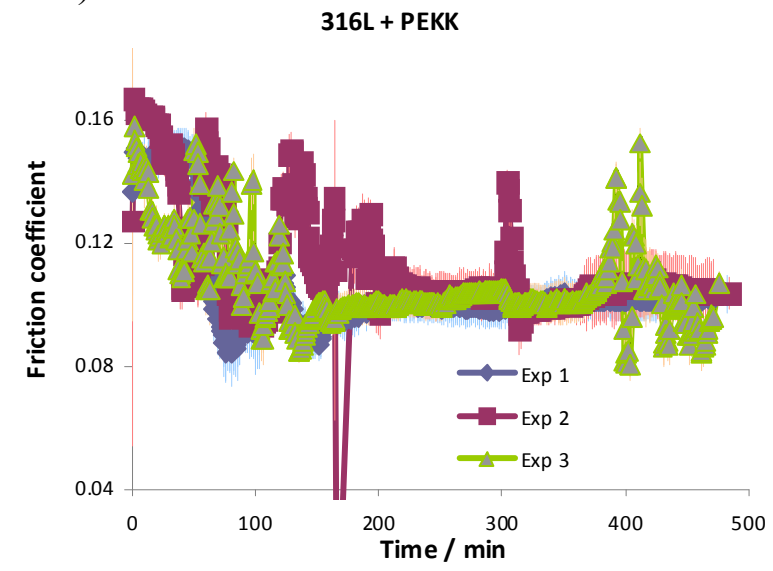

Figure 4: Friction coefficient vs. duration of friction tests with 316L SS against a) UHMWPE;

Figure 5 presents a summary of the friction coefficient evolution for all materials couple during 60 minutes (Average 1-60) and during the complete test duration (Average 500). First of all, the friction coefficient of UHWMPE/metal (Co-Cr alloy or 316L or Ti-6Al-4V, TA6V)

1 is the lowest, approximately 2 times lower than the ones of PAEK/metal couples in average.

2 As far as PEKK CF 30\% / metal couples is concerned, its behavior is different since the 

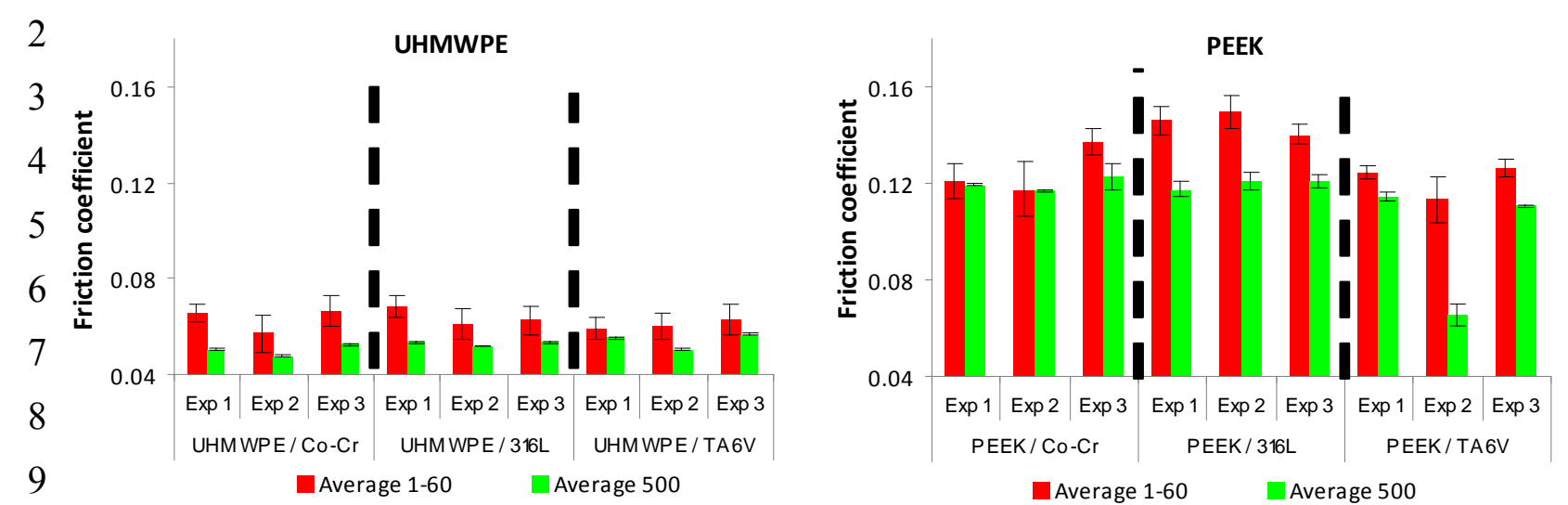

10

11

c)
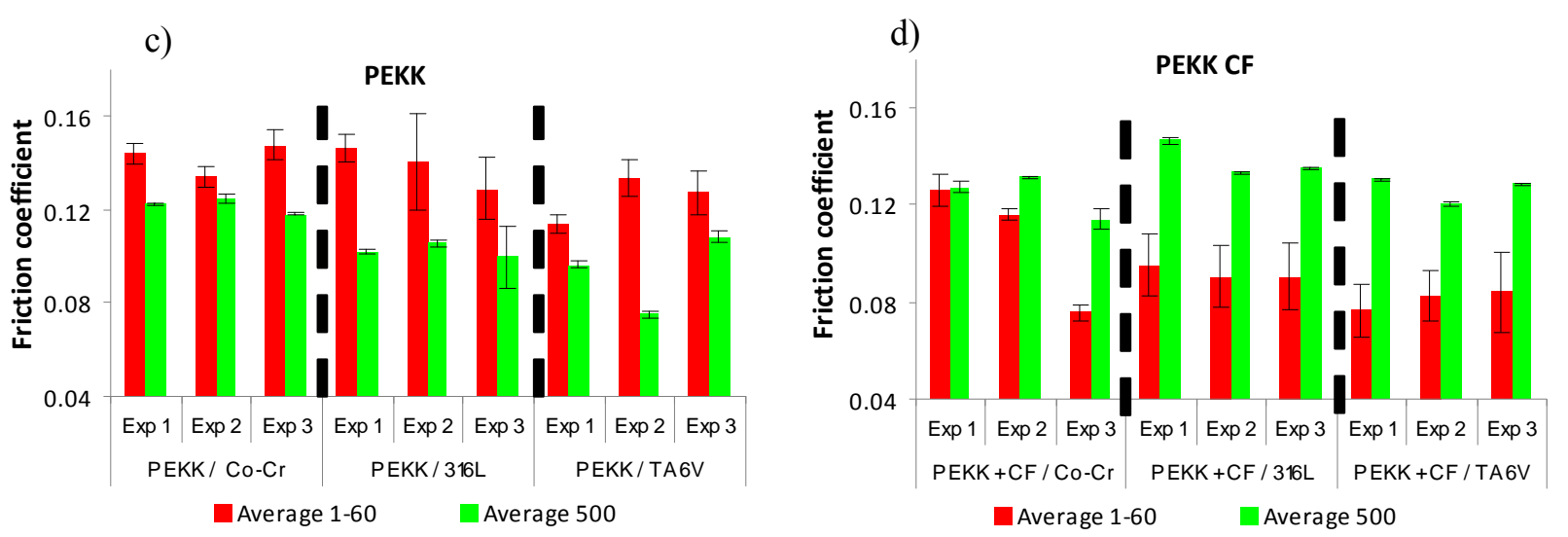

Figure 5: Friction coefficient for all materials couples; Average 1-60: mean of friction coefficient during the first 60 minutes; Average 500: mean of friction coefficient during the complete test duration; a) UHMWPE; b) PEEK; c) PEKK; d) PEKK + CF $30 \%$.

Therefore, the effect of the debris generation, between both materials in contact, is significantly different for PEKK composite. Indeed, if the friction coefficient decreases according to the time, it means that the third body might play the role of a lubricant. In the case of PEKK CF $30 \% /$ metal, on the contrary, the friction coefficient increases and, consequently, the third body seems play the role of abrasive particles, probably due to the carbon fibers against a metallic alloy. Sometimes, as could be seen in Figure $5 \mathrm{~b}$ ) for the PEEK / TA6V couple, a discrepancy is highlighted within the 3 experiments performed for each contact type. It is the reason why, to be able to explain the evolution of the friction 
1 coefficient, numerous tests have to be carried out for the same contact type. Finally, the trend

2 obtained from the average friction coefficient could be entrusted.

3 So as to validate or not the hypotheses made on the evolution of the friction

4 coefficient, the wear rate of polymer material will also be investigated.

\subsection{Wear rate analysis}

The friction coefficient is not sufficient to describe the wear behavior of materials

7 couple since even if the friction coefficient is weak, the wear rate could be the highest when a

8 material couple series is compared to another. It is the reason why, in this part, we will focus

9 our interest, about the wear rate. It is worth noting that the wear of metallic alloy could not be measured.

Figure 6 a) presents the wear zone of the PEKK CF $30 \%$, the pin being a $316 \mathrm{~L}$ ball. As one can see, the wear track area is heterogeneous. In Figure 6 b) the reference line defines

13 the width, the depth and the wear surface of a wear track zone. These three parameters will be 14 investigated for all contacts type. Figure 7 a) depicts the wear rate, i.e. the wear volume per 15 unit of normal load and per unit of length (wear distance) for all materials couples. Figures 7 16 b) and c) present respectively the width and the highest depth of the wear track area, obtained 17 from the 3D profilometry scans. 
1

a)

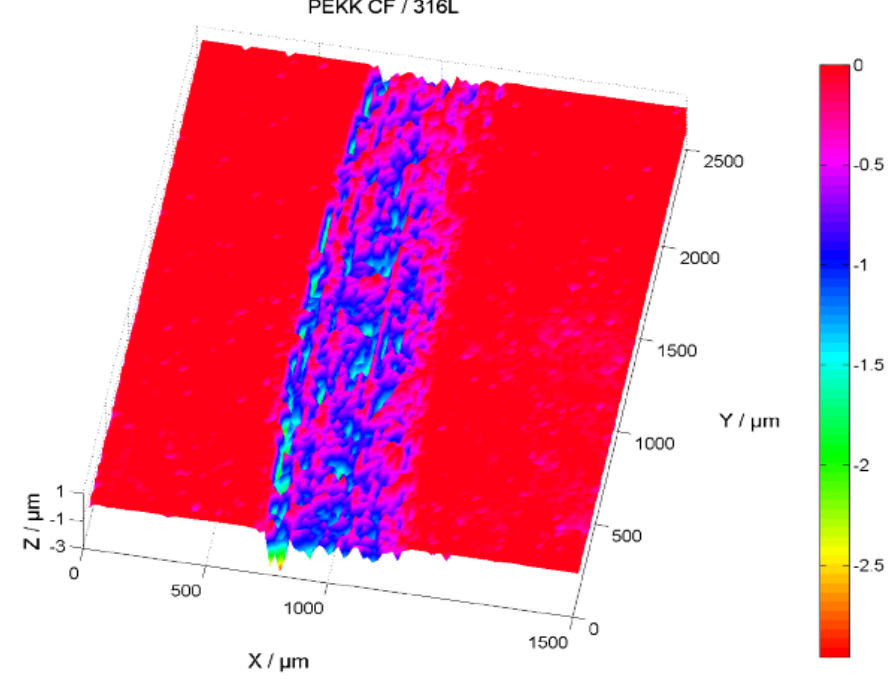

b)

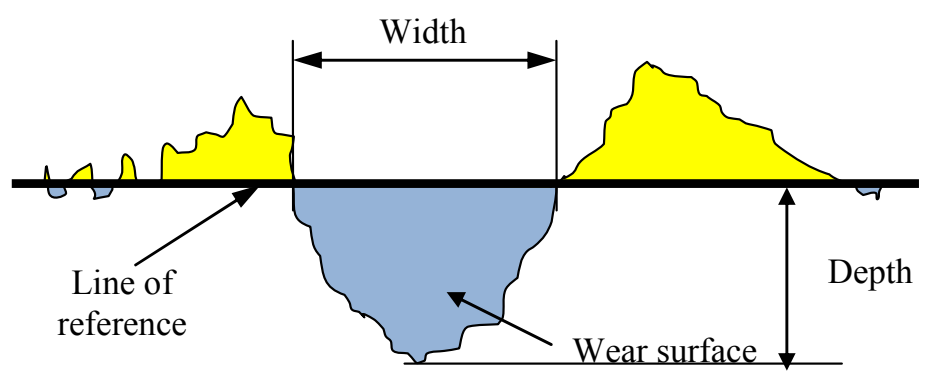

8 Figure 6: a) wear track area of a PEKK CF $30 \%$ sample (contact PEKK CF $30 \% / 316 \mathrm{~L}$ ), the $9 \quad z$-scale is in $\mu \mathrm{m}$; b) Typical $2 \mathrm{D}$ view of $\mathrm{x}$-z plane from a wear zone.

10

a)

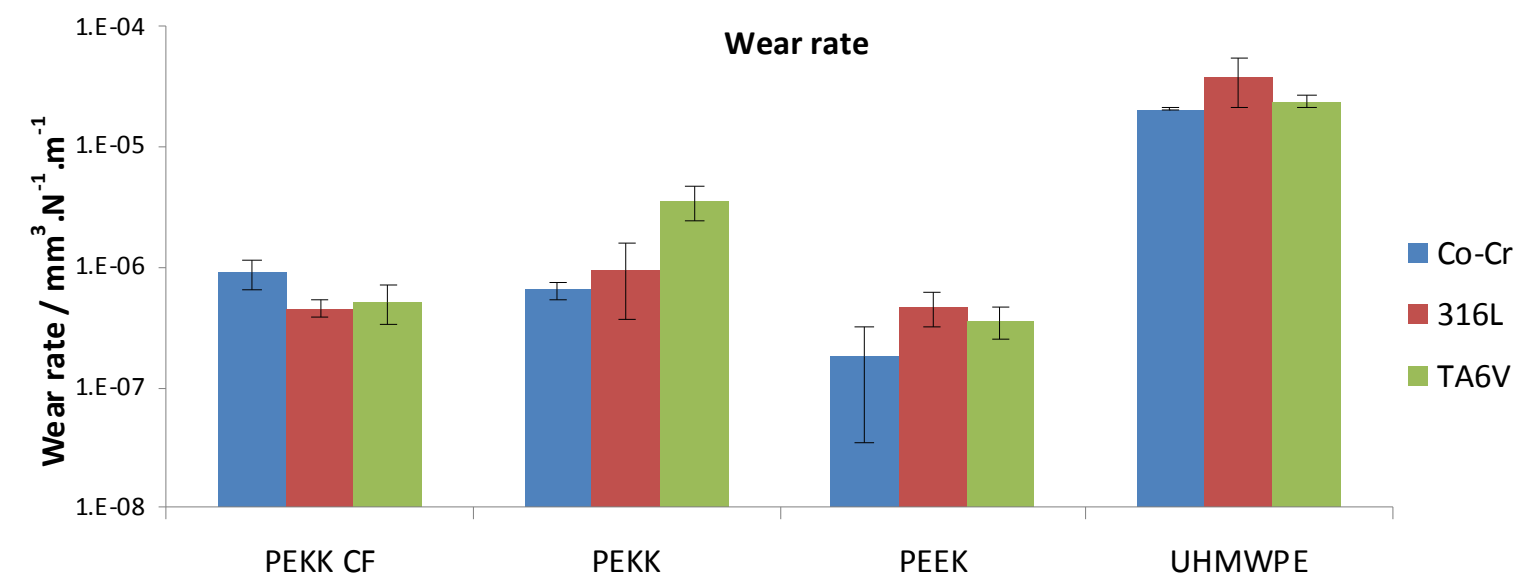

11

12
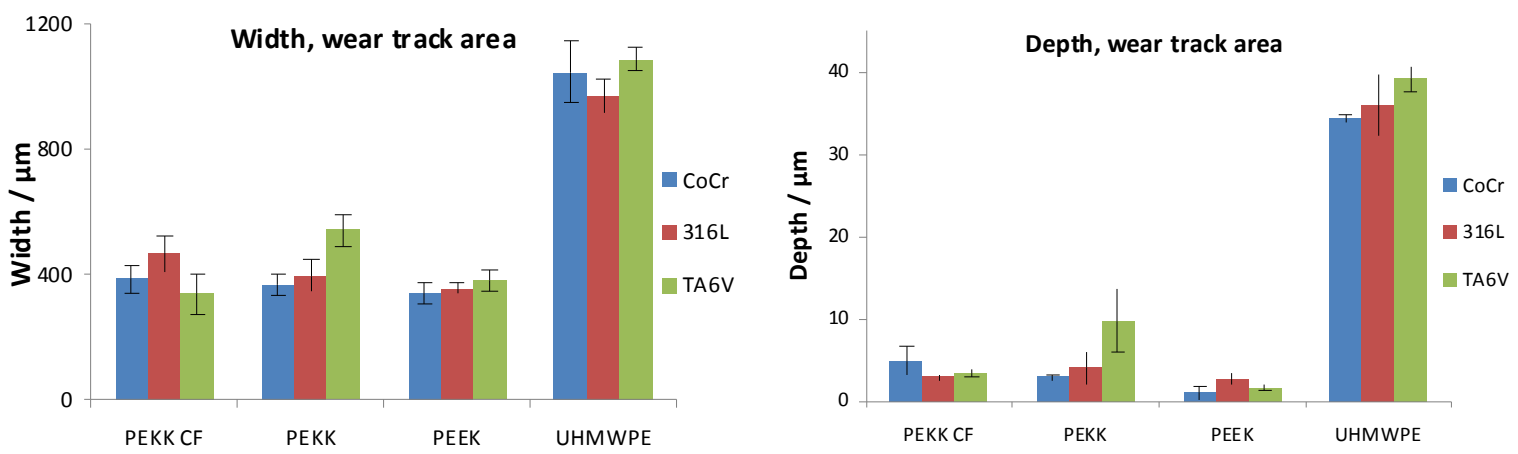

13

14 Figure 7: a) wear rate $\mathrm{mm}^{3} \cdot \mathrm{N}^{-1} \cdot \mathrm{m}^{-1}$ (logarithm scale) for all materials couples, the discrepancy 15 is the standard deviation; b) width of the wear zone; c) highest depth of the wear zone. 
1 First the results obtained for PAEK polymers should be compared with the wear rate

2 measured by Zhang et al [11]. From the wear rate values in Figure 7, it is clearly highlighted

3 that the UHMWPE is the most worn material. The UHMWPE wear rate is 10 times higher

4 than the ones of PEKK + CF $30 \%$, PEKK and PEEK. The PEEK material seems to involve

5 the lowest wear rate against all metallic material. Table 12 exhibits the Anova tests

6 (confidence level of $95 \%$ ) results for both materials couples. The wear rates of UHMWPE

7 polymer discs against any metallic pins are different from the ones of PAEK polymer discs.

8 Thus, if we compare PEEK and PEKK, the PEKK / 316L wear rate is not significantly

9 different from PEEK / 316L, Co-Cr and TA6V. Finally, a rank, from the highest to the lowest

10 wear rate, could be assumed from these experimental values: UMHWPE >> PEKK, PEKK /

11 CF, PEEK.

12

13

14

15

16 


\begin{tabular}{|c|c|c|c|c|c|c|c|c|c|c|c|}
\hline & $\begin{array}{l}\text { PEKK CF } \\
/ \mathrm{CoCr}\end{array}$ & $\begin{array}{l}\text { PEKK CF } \\
/ 316 \mathrm{~L}\end{array}$ & $\begin{array}{l}\text { PEKK CF } \\
\text { / TA6V }\end{array}$ & $\begin{array}{l}\text { PEKK / } \\
\text { CoCr }\end{array}$ & $\begin{array}{l}\text { PEKK / } \\
316 \mathrm{~L}\end{array}$ & $\begin{array}{l}\text { PEKK / } \\
\text { TA6V }\end{array}$ & $\begin{array}{l}\text { PEEK / } \\
\text { CoCr }\end{array}$ & $\begin{array}{l}\text { PEEK / } \\
316 \mathrm{~L}\end{array}$ & $\begin{array}{l}\text { PEEK / } \\
\text { TA6V }\end{array}$ & $\begin{array}{c}\text { UHMW } \\
\text { PE / } \\
\text { CoCr }\end{array}$ & $\begin{array}{c}\text { UHMW } \\
\text { PE4 } \\
316 \mathrm{~L}\end{array}$ \\
\hline $\begin{array}{c}\text { PEKK CF / } \\
316 \mathrm{~L}\end{array}$ & Yes & $\mathrm{x}$ & & & & & & & & & $\begin{array}{l}3 \\
4\end{array}$ \\
\hline $\begin{array}{c}\text { PEKK CF / } \\
\text { TA6V }\end{array}$ & No & No & $x$ & & & & & & & & 5 \\
\hline PEKK / CoCr & No & No & No & $\mathrm{x}$ & & & & & & & $\begin{array}{l}6 \\
7\end{array}$ \\
\hline PEKK / 316L & No & No & No & No & $x$ & & & & & & 8 \\
\hline PEKK / TAGV & Yes & Yes & Yes & Yes & Yes & $x$ & & & & & \\
\hline PEEK / CoCr & Yes & Yes & No & Yes & No & Yes & $x$ & & & & 11 \\
\hline PEEK / 316L & No & No & No & No & No & Yes & No & $x$ & & & 12 \\
\hline PEEK / TAGV & Yes & No & No & Yes & No & Yes & No & No & $x$ & & 14 \\
\hline $\begin{array}{l}\text { UHMWPE / } \\
\text { CoCr }\end{array}$ & Yes & Yes & Yes & Yes & Yes & Yes & Yes & Yes & Yes & $x$ & 15 \\
\hline $\begin{array}{c}\text { UHMWPE / } \\
316 \mathrm{~L}\end{array}$ & Yes & Yes & Yes & Yes & Yes & Yes & Yes & Yes & Yes & No & $\begin{array}{c}16 \\
\times \\
17\end{array}$ \\
\hline $\begin{array}{c}\text { UHMWPE / } \\
\text { TA6V }\end{array}$ & Yes & Yes & Yes & Yes & Yes & Yes & Yes & Yes & Yes & No & N8 \\
\hline
\end{tabular}

21 Table 12: Differentiation of wear rate between two materials couples. ANOVA test for the 22 same set of data presented in Figure 7 a). In cells marked yellow, there is significant 23 difference between values on level of confidence $95 \%$. 
The PEEK / Co-Cr wear rate seems to be the lowest even against PEKK CF / Co-Cr. This result has to be linked to the lowest value of $\mathrm{Ra}$ attributed to PEEK samples. From the tribological tests, Co-Cr seems to be the best counter part for PEKK, PEKK CF and PEEK. If we analyze the width and the depth of the wear track area from the polymer discs: one can conclude that the width for UHMWPE samples is 3 times higher than the ones for PAEK samples. Moreover, the depth for UHMWPE is 10 times higher than the ones for PAEK samples. Finally, the wear depth of UHMWPE is definitively the highest. A representative plot in Figure 8 shows the correlation between the friction coefficient and the disc wear rate. The lowest wear rate corresponds to the couple PEEK vs. Co-Cr so that this materials couple should be investigated for the artificial hip joint: $\mathrm{Co}-\mathrm{Cr}$ could replace the femoral head and PEEK the acetabular cup. A future work could investigate the wear behavior of the PEEK CF discs against metallic pins. The highest wear rates are assigned to the UHMWPE couples. Figure 8 highlights that the lowest friction coefficient, for investigated materials, is not related to the lowest wear rate. In fact the trend is the opposite. Finally after tests and comparisons, the volumetric measurements thanks to a mechanical profilometer (or optical) seems to be the best method to determine the wear volume for the polymer material. Indeed, the weight gain of the polymer samples during tests does not allow measuring correctly the weight variations, due to hieratic water absorption.

Concerning hip prosthesis, head-cup joint for instance, some previous investigations [12] were carried out to evaluate the lifetime of a PEEK CF cup against a head made of metal or alumina. PEEK CF highlights the advantage to be not degradable after sterilization, especially $\gamma$ radiation, a requirement for implanting a biomaterial [13]. The biocompatibility, interactions with cells as osteoblasts, was investigated and satisfying results were found $[2,3]$. If PEEK is still now implanted for spinal cages, some investigations are carried out for increasing the cytocompatibility in order to reach the same level than the one of titanium [3]. 


\section{Correlation of friction coefficent vs. disc wear rate}

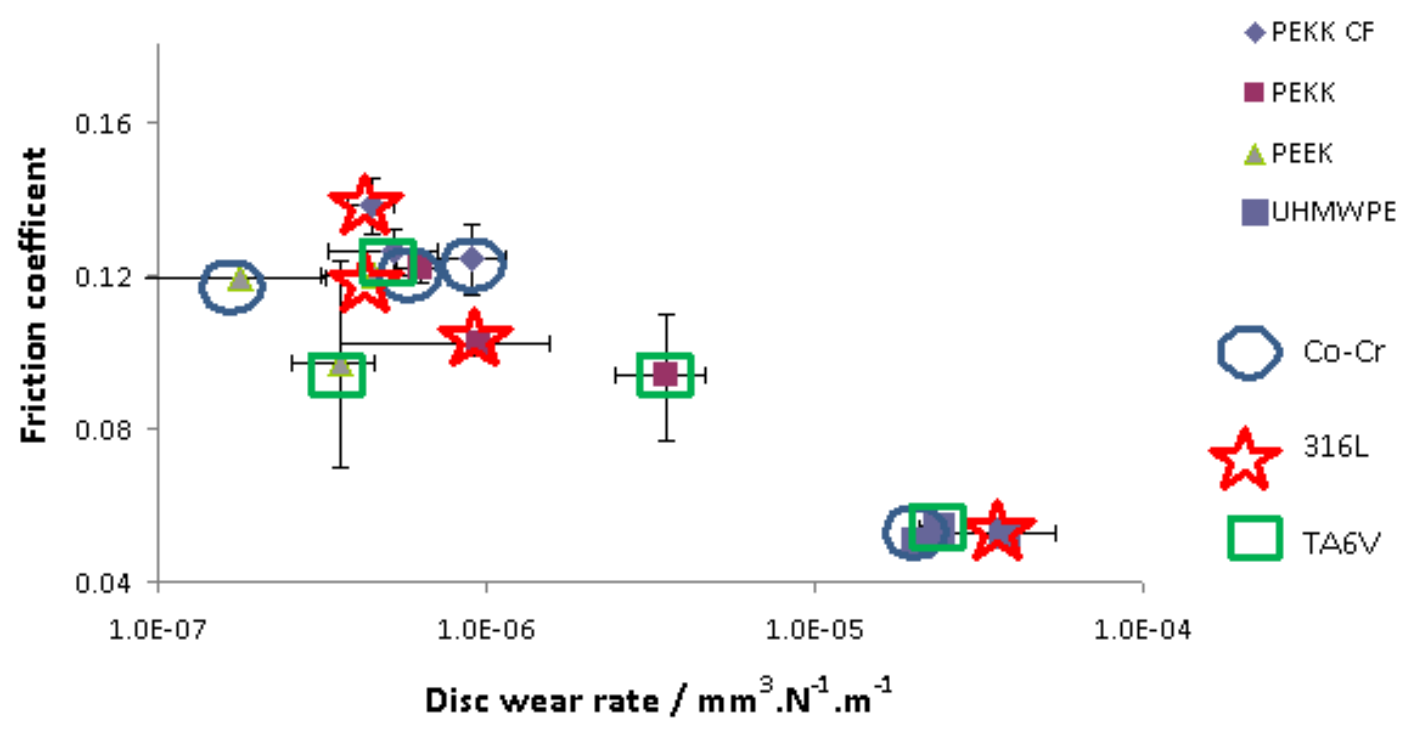

Figure 8: Friction coefficient vs. disc wear rate for the 9 couples of materials; blue circle, red star and green square are respectively related to $\mathrm{Co}-\mathrm{Cr}, 316 \mathrm{~L}$ and TA6V (Ti-6Al-4V); the discrepancy is the standard deviation

In an international multicenter clinical study, a cup made of PEEK CF was implanted against an alumina head for replacing a hip joint. . The wear depth in the retrieved cup of PEEK/CF showed a value of $0.057 \mathrm{~mm}$ a year [14], to be compared, for example, with $0.174 \mathrm{~mm}$ a year for a UHMWPE cup [15]. Knowing that the UHMWPE wear volume is within the range of $58-140 \mathrm{~mm}^{3} /$ year [16], the PAEK wear volume is expected to be minimum 2 times lower than that of UHMWPE, which is a huge improvement for implant lifetime. It is worth noting that the gap between the linear and volume wears of retrieval implants is drastically different than the ones from the tribological tests presented in this study. However in the current tests, the difference between wear rate of UHMWPE and PAEK is in the range of magnitude about 10 times, which means that the volumetric wear rate of PAEK, should be lower than the one of UHMWPE. Consequently, PAEK polymers, should be considered as promising materials for artificial hip cup. Particular investigations should be carried out for testing PEKK or PEKK CF cups in in vitro conditions. Future investigations will aim at improving the wear rate of 
PAEK materials taking into account that the actual shape of cup against a metallic or ceramic head and considering the actual loading conditions, that is thanks to a hip walking simulator.

The next part of the paper will be dedicated to the morphological analyses of the wear track area.

\subsection{Microscopic analyses of wear track areas}

The pins and the discs surfaces were observed by optical and scanning electron microscope. For comprehension purpose, the following discussion will be divided in two parts: the first about the polymer discs and the second one about the metallic pins.

\subsubsection{Polymer discs}

Figure 9 shows pictures of the polymer discs surface after wear tests. The type of counter part, i.e. metallic pin, is indicated in the left column. Different wear mechanisms could be clearly distinguished in Figure 9. Fatigue waves are only seen on the UHMWPE wear track area. This typical tribological behavior of UHMWPE was already mentioned by Wang et al [17]. On the contrary, debris or scratches are hardly observed for UHMWPE in comparison with other polymer materials, i.e. PAEK. It is worth noting that for PEEK perpendicular scratches are highlighted, especially for $\mathrm{PEEK} / \mathrm{Co}-\mathrm{Cr}$ and $\mathrm{PEEK} / 316 \mathrm{~L}$ contacts. These scratches are pretty long, up to few hundred of micrometers, which indicate that delamination is a part of the wear process for PEEK. For instance, this kind of delamination process does not occur for PEKK. The PEKK CF sample exhibits a particular wear track area. No significant difference is seen when comparing Co-Cr, $316 \mathrm{~L}$ and Ti-6Al-4V contacts. It can be seen that carbon fibers were broken in the transversal direction and that some fibers were pulled out from the polymer matrix. Such behavior involves that fibers, $100 \mu \mathrm{m}$ long and 
approximately $10 \mu \mathrm{m}$ in diameter could have been ejected from the disc and could have played the role of an abrasive third body. It is worth noting that this third body, that is carbon fibers of different lengths, may be a key point if the biocompatibility is considered. In this study, this key point will not be considered.

Figure 10 presents pictures of PEKK and PEKK CF samples. A special attention should be paid to these particular polymer materials as they highlight the impact of carbon fibers. Traces on pure PEKK polymer were not clearly defined - scratches became visible only at high magnification and found homogenous and straight. Any other features were visible. The borders of wear track were characterized by big spacing and rough edges of scratches, incrusted particles could also be found inside the wear track area.

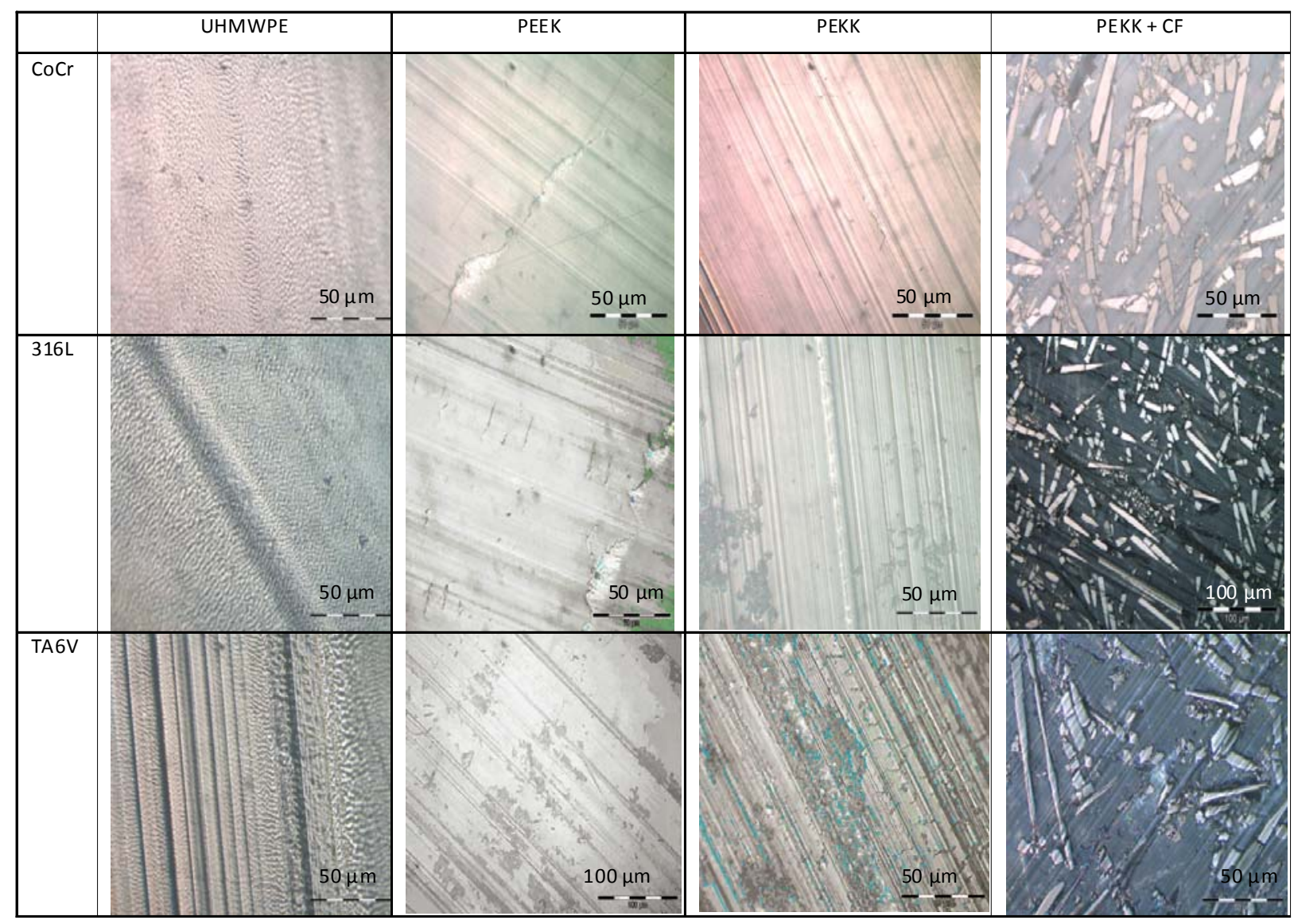

Figure 9: pictures of the wear track area of polymer samples. 
The PEKK $+\mathrm{CF}$ composite track is pretty different. High magnifications reveal carbon fibers in all stages of deterioration: some fibers incorporated in material were pulled out and then were fragmented. The material loss around fibers is especially well depicted. The bottom of track resembles mortar where debris are being collected and ejected at the rim of the contact. It is worth noting that no metal particles on polymer were analyzed by EDX analysis.

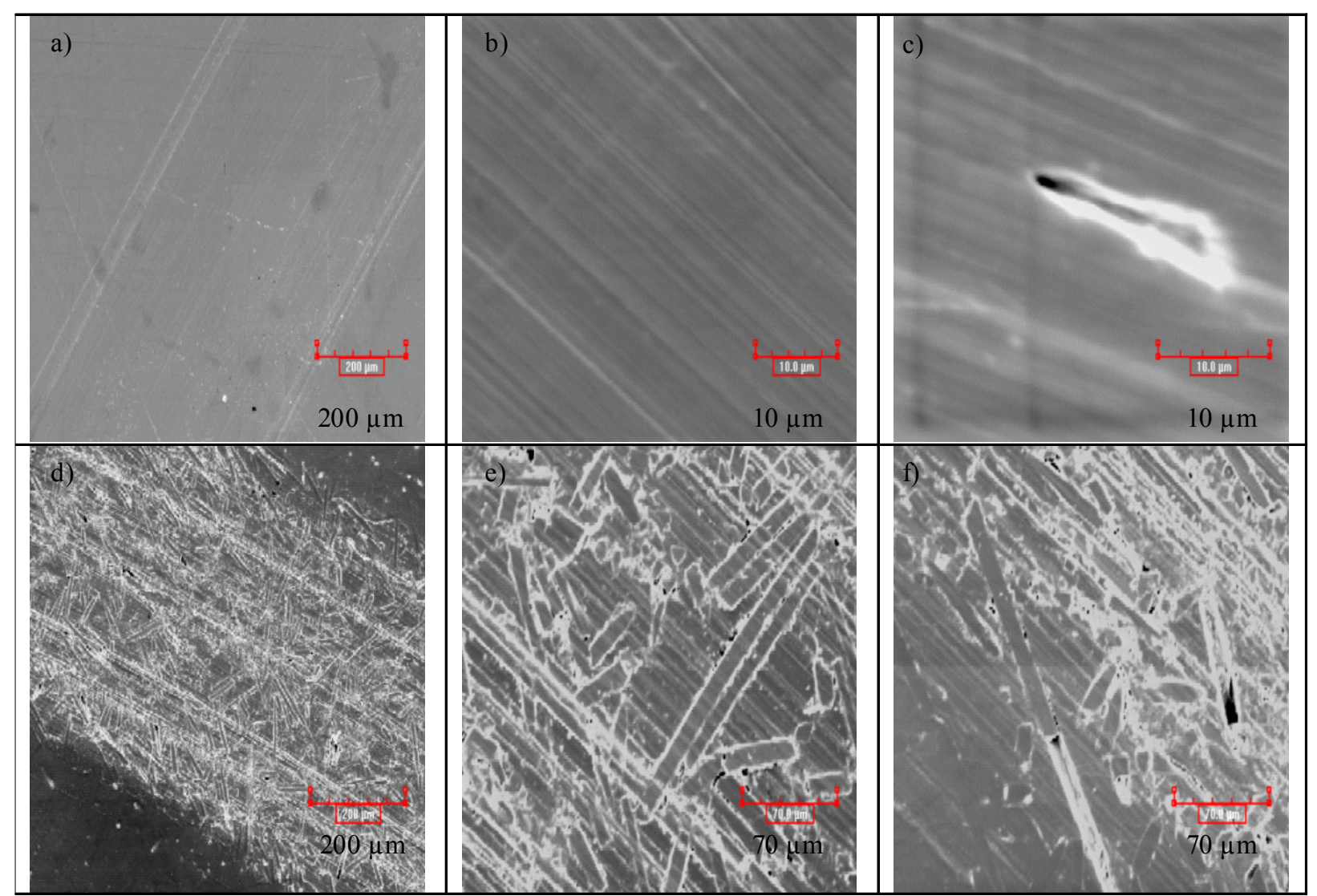

Figure 10: SEM images of wear track area of polymer samples; a), b), c): PEKK samples; d), e), f): PEKK CF 


\subsubsection{Metallic pins}

As the contact pressure on the pin is lower than its ultimate tensile strength (see Table 10), the metallic material, Co-Cr, 316L and Ti-6Al-4V, does not undergo any significant degradations. Figure 11 presents samples of Co-Cr, 316L and another 316L against PEKK CF, PEKK and PEEK respectively. In figure 11 left picture, scratches and grooves could be seen on the Co-Cr surface. It is worth mentioning that the Co-Cr sample against PEKK CF is the most damaged one compared to other polymers without carbon fibers,. The wear track area of other metallic pins (friction against PEKK CF) exhibits the same pattern. Obviously, pictures of metallic samples against UHMWPE were not shown because no damages were visible. From these images of Co-Cr surface, one may suggest that femoral head made of Co$\mathrm{Cr}$ against composites polymer as cup, would involve increased wear of metal compared to the standard couple Co-Cr or 316L against UHMWPE. This is the reason why one should recommend investigating materials couples via in vitro tests in conditions as close as possible to a hip joint with head and cup.
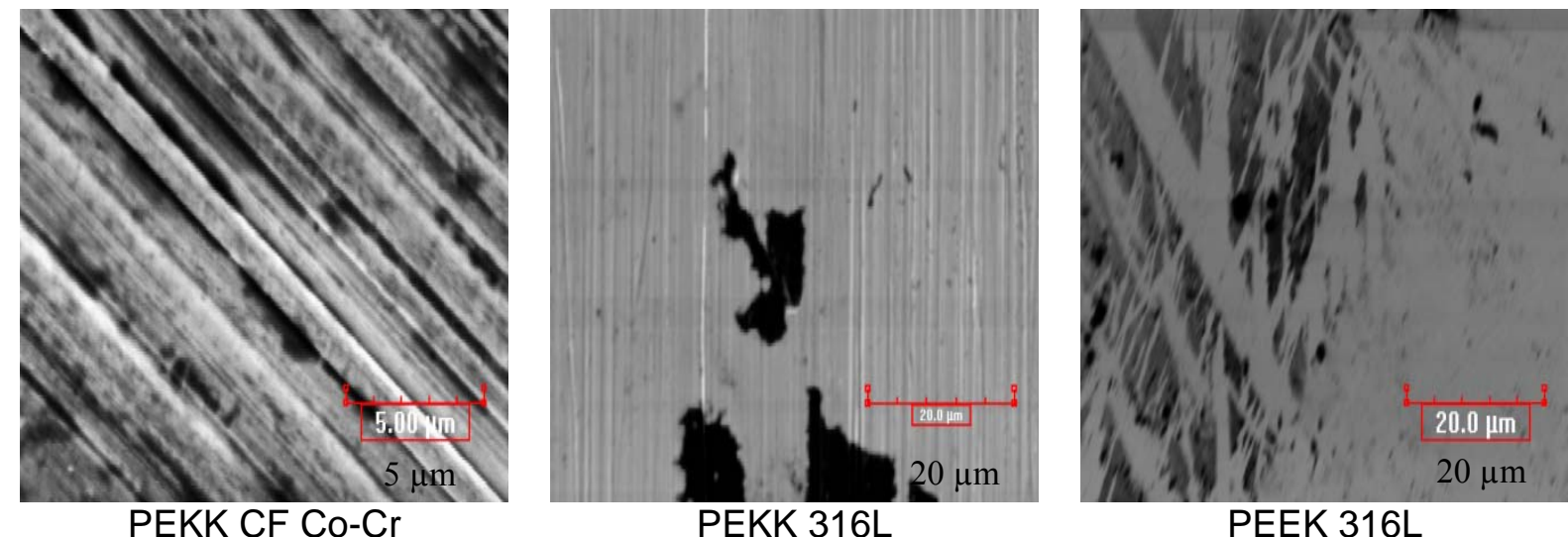

PEEK 316L

Figure 11: SEM images of metallic pins, black patchs are corrosion debris and proteins

The wear mechanisms will be investigated in the next part. 


\subsection{Wear mechanisms-overview}

A summary of the observations made on disc and pins deterioration is presented in Table 13. It was established from optical microscopy observations of both counter parts as well as friction coefficient recording.

The UHMWPE disc/metal pin contact involves a common behavior that is the UHMWPE disc surfaces, after tribological tests, exhibit fatigue waves and abrasion. The metallic surfaces do not suffer any degradation and no corrosion insights.

On the other hand, insights of abrasion were highlighted on all PAEK disc samples; abrasion is the main wear mechanism. The PEEK samples exhibit delamination and debris, signs of corrosion. Concerning the PEKK discs, two conclusions may be drawn: 316L and Ti$6 \mathrm{Al}-4 \mathrm{~V}$ involve continuous delamination and relatively homogeneous debris layer, visible after triboblogical tests. PEKK discs, against $\mathrm{Co}-\mathrm{Cr}$, do not exhibit continuous delamination and debris that adhere to the wear track area (PEKK debris do not stuck to the samples). The medium (bovine serum) could play a significant role about the potential of zero charge of this polymer. Additional investigations are required to validate this assumption. Finally, the PEKK CF samples exhibit abrasion and a continuous debris layer. The metallic heads were significantly damaged by corrosion. The carbon fibers, hard particles, could play a significant role for destroying the protective oxides layer of the metallic head.

As this behavior was observed for all tests, the tribology of the contact could only be due to the composite material. Moreover, the debris layer found on discs results (PEKK discs) from an extensive corrosion of pins and delamination is clearly correlated to variations of the friction coefficient during tests, as seen in Figure 4. 


\begin{tabular}{|c|c|c|c|c|c|c|}
\hline Polymer & Metallic alloy & Fatigue & Abrasion & Debris & Delamination & Corrosion of Head \\
\hline \multirow{3}{*}{ PEEK } & $316 \mathrm{~L}$ & & +++ & & $+0+$ & \\
\hline & Co-Cr & & +++ & $0+0$ & $00+$ & $0++$ \\
\hline & Ti-6Al-4V & & +++ & ++0 & $00+$ & ++0 \\
\hline \multirow[t]{3}{*}{ PEKK *** } & $316 \mathrm{~L}$ & & $\overline{+++}$ & +++ & $\overline{0++}$ & $\overline{+++}$ \\
\hline & Co-Cr & & +++ & & +++ & ++0 \\
\hline & Ti-6Al-4V & & +++ & $+0+$ & +++ & +++ \\
\hline \multirow[t]{3}{*}{ PEKK + FC } & $316 \mathrm{~L}$ & & +++ & +++ & & +++ \\
\hline & $\mathrm{Co}-\mathrm{Cr}$ & & +++ & +++ & & +++ \\
\hline & Ti-6Al-4V & & +++ & +++ & & +++ \\
\hline \multirow[t]{3}{*}{ UHMWPE } & $316 \mathrm{~L}$ & +++ & +++ & & & \\
\hline & Co-Cr & +++ & +++ & & & \\
\hline & Ti-6Al-4V & +++ & +++ & & & \\
\hline
\end{tabular}

Table 13: Analyses of worn surfaces. 3 items for each experiment, + : sign, 0 : no sign, $* * *$ : big oscillations of friction coefficient were observed, empty square: no sign.

The Figure 12 presents the summarized wear behavior proposed. In the case of UHMWPE, where pressure exceeds tensile strength of material, disc yields and deforms creating a wide path. As far as degradation is concerned, it is due to low-cycle fatigue mechanism. However the darkening and murking of the medium during experiment suggest that debris were produced and accumulated in bovine serum. Because of the UHMWPE low density, debris of UHMWPE would float onto medium and not stay close to the wear track area. This would diminish the influence of debris on pins' deterioration, whereas more dense PEAK's debris would become "incrusted" into wear track and induce abrasion and corrosion of metallic pins. Moreover the surface charges on the debris should be drastically taken into account for these aggregated particles on the polymer samples. The considered medium, i.e. $\mathrm{pH}$, proteins and ions concentrations, should play a significant role on this debris adsorption. So as to conclude with the PEKK CF, after short running-in period, the whole track is covered with carbon fibers debris and the pins surface is homogenously damaged, involving a more severe corrosion of metallic pins than the ones with the UHMWPE/metal contact.

When the average pressure is comparable with the material tensile strength, like for PEEK and PEKK, wear remains local. Typically for PEKK disc, this is materialized by big 
oscillations resulting from the evolution of the friction coefficient. Neither UHMWPE nor $\mathrm{PEKK}+\mathrm{CF}$ exhibit this behavior due to the "global" wear mechanism from very beginning of experiment. Two mechanisms are possible - delamination and debris production, knowing that both could take place at the same time. None of these mechanisms seems to be dominant.. However, as discussed previously, debris production could explain the extensive corrosion of pins. If the oxides protective layer of pin is constantly damaged then corrosion occurs. One can imagine that the passive layer could be destroyed by presence of hard particles (carbon fiber debris in composite) or wear by high pressures (all PAEK materials).

In addition, the differences observed in terms of wear mechanisms between PEKK and PEEK material could be affected by some intrinsic physical interactions between polymer chains. Indeed, PEKK ketone groups could be in meta and para configurations whereas, for PEEK, only para configuration is possible (see Figure 1) Consequently, configurations of polymer chains are expected to be different between PEEK and PEKK and so the crystalline phases should be different [18]. In further work, additional investigations on the XRD should get insights on this point. 


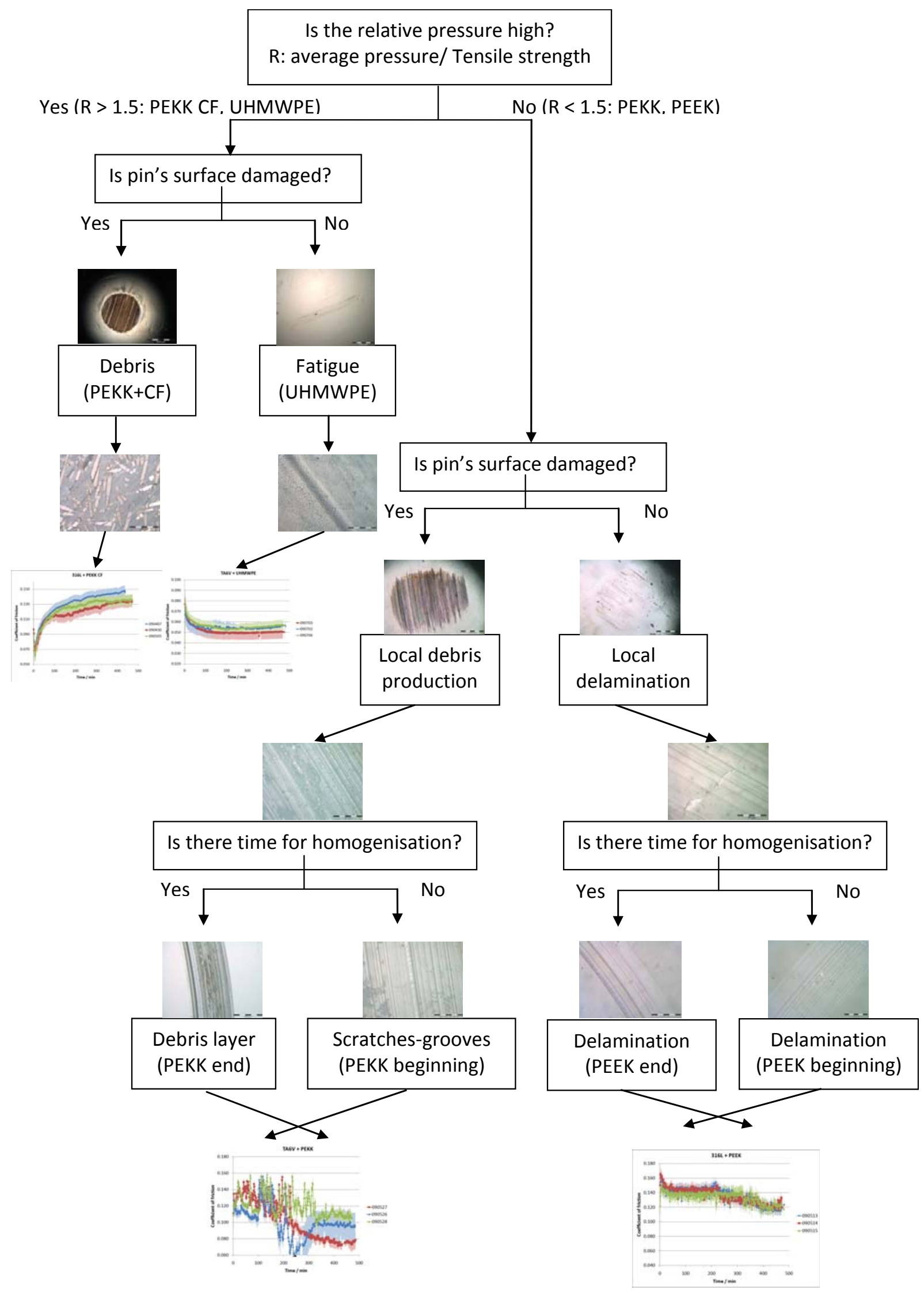

Figure 12: summarized wear behaviors of tested materials. 
When experiments are maintained long enough, local areas of delamination or debris layer become continuous, which result from the stabilization of the friction coefficient. One originality of this paper lies in the fact that the wear experiments performed were significantly longer in comparison to what is described in bibliography, typically 2 hours [19-21]. Such long experiments give a good insight into the tribological behavior of PAEK and composites materials.

As a conclusion of these studies and previous ones, one can say that the carbon fibers play the role of lubricant in the contact at the beginning of tests, low friction coefficient. However, long investigations, up to 5 hours, were already not carried out, this is the main improvement of this study. According to results about the composite with carbon fibers, this work may suggest that lubricating properties of carbon fibers are only temporal. The significant problem should be, concerning the composite polymer, the wear of metallic counterpart due to abrasive behavior of carbon fibers. After long time of prosthesis usage, unfavorable effects of debris presence, mainly fibers, would be more harmful than beneficial due to questionable lubrication.

\section{Conclusion}

These tribological investigations showed some interesting insights into the behavior of PAEK materials, including composite polymer PEKK and carbon fibres $30 \%$. These PAEK materials were potentially used as implants, artificial hip joint for example.

Superior properties of the materials from PAEK group seem incontrovertible in comparison with the usual UHMWPE used for acetabular cup. They are more wear resistant, producing less debris. PAEK wear rates are 10 times lower than the one of UHMWPE. It could be beneficial concerning contaminating living organism, interactions between debris 
and cells. This assumption will be assessed in a future work taking into account the size and the shape of debris particles. The PAEK materials class also meets basic needs concerning volume wear for the development of new Hard-on-Soft hip prosthesis.

The study of the mechanisms of deterioration also gave satisfying explanations of the wear behavior. One might pay attention to link mechanical properties and the ratio of average contact pressures on tensile strength to the wear behavior of polymer materials. In terms of this ratio defined above on Table 10, UHMWPE and PEKK + CF belong to the same class. It means that the composite polymer material is submitted to high contact pressure. The role of the third body, especially carbon fibres, in the prediction of the wear rate on a long period of time, should be investigated through additional tests,.

The key-point for introducing PEEK or PEKK or composites with carbon fibers in hip prothesis should be biological response of living cells to those materials. Therefore the next stage that consists in introducing PEKK or PEEK- as acetabular cup on orthopedy market could be undertaken. Nevertheless, the exact wear mechanism and more data on materials behavior in actual prosthesis have to be examined in order to accomplish this challenge. About the tribocorrosion tests, this study cast light on the passive layer reconstruction hypothesis. Electrochemical follow-up of metal samples should be very interesting to highlight particular corrosion behavior in presence of carbon fibers as a third body. At the interface of carbon fibers, there is usually greasing and protective specimens that enhance procedure of composite manufacturing. This key-point should change the adhesion of carbon fibers with the polymer matrix. Finally, very long experiments with low pressure could reveal whether other mechanisms of deterioration are dominant when pressure is closer to the real pressure in hip joints. As wear would be very weak, other variable - namely time - should be increased and the experiment could be carried out on hip walking simulators. Anatomic position of components would prevent debris accumulation, and the geometrical set-up would 
be more similar to clinical case. The tribological behavior could be entirely different with acetabular cup design due to particular sample geometry compared to pin-on-disk samples.

\section{Acknowledgements}

The authors want to acknowledge Ms. Prisca Leveque for the polishing assistance. Moreover they are grateful to the Region Rhône-Alpes and Carnot Institute Cetim, Centre Technique des Industries Mécaniques, for the financial and technical support and providing the opportunity to carrying on the research activities between two Carnot Institutes Cetim and M.I.N.E.S. 


\section{References}

[1] L. Blunt, P. Bills, X. Jiang, C. Hardaker, G. Chakrabarty, The role of tribology and metrology in the latest development of bio-materials, Wear, 2009, 266, 424-431

[2] S.M. Kurtz, J.N. Devine "PEEK biomaterials in trauma, orthopedic, and spinal implants" Biomaterials 28 (2007) 4845-4869

[3] K.B. Sagomonyants, M.L. Jarman-Smith, J.N. Devine, M.S. Aronow, G.A. Gronowicz, The in vitro response of human osteoblasts to polyetheretherketone (PEEK) substrates compared to commercially pure titanium, Biomaterials, 2008, 29, 1563-1572

[4] S. Utzschneider, F. Becker, T.M. Grupp, B. Sievers, A. Paulus, O. Gottschalk, V. Jansson, Inflammatory response against different carbon fiber-reinforced PEEK wear particles compared with UHMWPE in vivo, Acta Biomaterialia, article in press, doi:10.1016/j.actbio.2010.06.002

[5] A.P. Harsha, U.S. Tewari, Tribo performance of polyaryletherketone composites, Polymer Testing, 2002, 21, 697-709

[6] J. Geringer, F. Atmani, B. Forest, Friction-corrosion of AISI 316L/bone cement and AISI 316L/PMMA contacts: Ionic strength effect on tribological behavior, Wear, 2009, 267, 763-769

[7] J. Geringer, L. Navarro, B. Forest, Influence de la teneur en protéines de solutions physiologiques sur le comportement électrochimique du Ti-6Al-4V : reproductibilité et représentation tempsfréquence, Matériaux \& Techniques, 2010, 98, 59-68

[8] H. Hertz, Uber die berührung fester elasticher Körper, J. Reine und Angewandte Mathematik, $1882,92,156-171$.

[9] D.A. Hills, D. Nowell, A. Sackfield, Mechanics of Elastic Contacts, Butterworth-Heinemann Ltd, Oxford, 1993, p.53-55.

[10] K.L. Johnson, Contact Mechanics, Cambridge University Press, Cambridge, 1985-1988, p.99104.

[11] R. Zhang, A.M. Häger, K. Friedrich K, Song Q, Dong Q, Study on tribological behavior of plasma-treated PEEK and its composite, Wear, 1995, 181-183, 613-623

[12] Wang A, Lin R, Polieni V.K, Essner A, Stark C, Dumbleton J.H, Carbon fiber reinforced polyether ether ketone composite as a bearing surface for total hip replacement, Tribology International, 1998, 31, 661-667

[13] Godara A, Raabe D, Green S, The influence of sterilization processes on the micromechanical properties of carbon fiber-reinforced PEEK composites for bone implant applications, Acta Biomaterialia, 2007, 3, 209-220

[14] Pace N, Marinelli M, Spurio S, Technical and Histologic Analysis of a Retrieved Carbon FiberReinforced Poly-Ether-Ether-Ketone Composite Alumina-Bearing Liner 28 Months After Implantation, The Journal of Arthroplasty, 2008, 23, 151-155

[15] Manning D.W, Chiang P.P, Martell J.M, Galante J.O, Harris, W.H, In Vivo Comparative Wear Study of Traditional and Highly Cross-linked Polyethylene in Total Hip Arthroplasty, The Journal of Arthroplasty, 2005, 20, 880-886

[16] Bragdon C.R, Jasty M., Kawate K, McGrory B.J, Elder J.R, Lowenstein J, Harris W.H, Wear of retrieved cemented polyethylene acetabula with alumina femoral heads, The Journal of Arthroplasty, 1997, 12, 119-125

[17] Wang A, Essner A, Polineni V.K, Stark C, Dumbleton J.H, Lubrication and wear of ultra high molecular weight polyethylene in total joint replacements, Tribology International, 1998, 31, 17-33

[18] Z. Stephen, D. Cheng, H. Rong-Ming, Polymorphism and crystal structure identification in poly(aryl ether ketone ketone)s", Macromolecular Chemical Physic, 1996, 197, 185-213

[19] H.B. Qiao, Q. Guo, A.G. Tian, G.L. Pan, L.B. Xu, A study on friction and wear characteristics of nanometer Al2O3 /PEEK composites under the dry sliding condition, Tribology International, 2007, $40,105-110$

[20] J.P. Davim, N. Marques, A.M. Baptista, Effect of carbon fibre reinforcement in the frictional behavior of Peek in a water lubricated environment, Wear, 2001, 251, 1100-1104

[21] Q.H. Wang, Q.J. Xue, W.M. Liu, J.M. Chen, The friction and wear characteristics of nanometer $\mathrm{SiC}$ and polytetrafluoroethylene filled polyetheretherketone, Wear, 2000, 243, 140-146 
